Covered in: Erih Plus; HeinOnline; CEEOL; RePEC; CrossRef; Google Scholar; KVK; WorldCat; ICI Journals Master List - Index Copernicus; EBSCO

2021, Volume 8, Issue 2, pages: 65-69 | https://doi.org/10.18662/eljpa/8.2/161

\section{Dangerous Recreational Activity} Lacramioara BALAN1

${ }^{1}$ Lecturer PhD, "Ştefan cel Mare" University of Suceava, Faculty of Law and Administrative Sciences, Suceava, Romania lacramioara.balan@,fdsa.usv.ro

\begin{abstract}
Drowning isn't the only danger in water - some aquatic animals can be deadly. The scuba diver who dies underwater poses a difficult diagnostic dilemma for investigating authorities and pathologists. Barotrauma caused by the failure of a gasfilled body cavity to equalize its internal pressure with changes in the ambient pressure is another cause of death.

Investigation should be thorough and follow a standardized outline. This investigation should include the victim's past medical and social history, dive profile, a detailed history of the terminal event and resuscitation efforts, environmental conditions, examination of the diving equipment and finally the autopsy.
\end{abstract}

Keywords: aquatic animals, scuba diver, barotrauma.

How to cite: Balan, L. (2021). Dangerous Recreational Activity. European Journal of Law and Public Administration, 8(2), 65-69. https://doi.org/10.18662/elipa/8.2/161 


\section{Dangerous aquatic life}

Drowning isn't the only danger in water-some aquatic animals can be deadly. Fatalities from coelenterate envenomation are rare. Fatal cases involving Physalia physalis (Portuguese man-of-war) and Chiropsalmus quadrumanus have been reported.

The autopsy findings in fatal cases were nonspecific (congested heavy lungs, acute passive congestion of (the viscera, subendocardial hemorrhage) except for the skin injury, which consisted of linear eruptions (Froede, 2003). In living victims, jellyfish envenomation produces a painful linear, erythematous, urticarial rash at the site of tentacle contact. In victims floating in the water who died from other causes, jellyfish contact produces no visible vital reaction, but the nematocysts may still be seen microscopically in the skin .

\section{Scuba diving}

Scuba (self-contained underwater breathing apparatus) diving is a popular recreational activity with an estimated 2.5 to 3.1 million certified divers. The scuba diver who dies underwater poses a difficult diagnostic dilemma for investigating authorities and pathologists (Wetli et al., 1999). Investigation should be thorough and follow a standardized outline.

This investigation should include the victim's past medical and social history, dive profile, a detailed history of the terminal event and resuscitation efforts, environmental conditions, examination of the diving equipment and finally the autopsy. The utility of going to the scuba death scene not only involves examining the body but, more importantly, inventorying and impounding all scuba gear.

This diver's weight belt was tied in a knot around his waist because the safety buckle did not work. Inventory the equipment and photograph it, preferably while it is still attached to the victim.

A visit to the death scene (or at least to the boat dock) is helpful for this purpose of documenting and gathering all the diving equipment.

The cylinder's air valve should be closed at the scene to prevent air loss from the tank. .Not all scuba divers die from drowning.

Clinicians may demonstrate reduced spirometry and compliance, hypoxaemia and characteristic radiological (plain x-ray or CT scan) abnormalities (Brubakk \& Neuman, 2002). These usually resolve rapidly (hours) in most cases. 
More frequently seen in older divers is SDPE. Most are in the 30-60 year age group and there may be an association with hypertension, ischaemic or other heart diseases or impaired respiratory function.

\section{Medical conditions disqualify from diving}

Several medical conditions disqualify patients from diving. Coronary artery disease (especially if the person has had recent angina or a previous $\mathrm{MI}$ ) is one such condition with its risk of sudden incapacitation by severe chest pain or rhythm disturbance. Approximately 10 to 20 percent of scuba fatalities involve individuals with severe coronary artery disease

Other conditions that normally disqualify a person from diving include seizure disorder, recurrent episodes of syncope, sickle cell disease, insulin-dependent diabetes mellitus, the presence of pulmonary cysts or blebs, severe chronic obstructive pulmonary disease with bullous emphysema, spontaneous pneumothorax, and certain middle-ear problems or surgery. Temporary disqualifying conditions include pregnancy and abdominal wall or inguinal hernias.

\section{Scuba diving equipment}

Scuba diving equipment is examined in less than 25 percent of fatalities, but this examination is important as the other investigations. The following procedures should be done with the scuba equipment:

- Immediately gather and impound all of the equipment;

- Inventory the equipment;

- If possible, photograph the victim with the equipment still on prior to removal;

- Record the final tank pressure and close the air valve to prevent air loss from the tank;

- Check the tank and regulator for defects;

- Check for a weight belt. Weigh it if available;

- Record the condition of the buoyancy compensator;

- Have the equipment examined by an unbiased knowledgeable diving expert who will provide a written report;

- Have air samples from the tank tested for correct partial pressures and presence of toxic gases;

- Have the internal lining of the tank inspected for corrosion

Examination of any computerized equipment carried by the deceased diver can be critical to the death investigation. 
A diver who died of air embolism used a DataMax Pro computer console during his dive, which provided important information about the dive.

\section{Barotrauma}

Barotrauma is tissue injury caused by the failure of a gasfilled body cavity to equalize its internal pressure with changes in the ambient pressure. The anatomic regions most commonly involved are the sinuses, middle ear, and lungs. Barotrauma of the lungs produces lifethreatening extra-alveolar air syndrome.

Extra-alveolar air syndrome can cause death or unconsciousness (and subsequent drowning) during ascent while breathing compressed air. The scuba regulator normally delivers air at ambient pressure and lung volume remains constant regardless of the depth. However, if you hold your breath and close your glottis (during a hasty or panicked ascent), then the obstructed alveoli will overexpand and burst, with air dissecting into the pulmonary interstitium. This air can enter the pleural cavities (pneumothorax), mediastinum (pneumomediastinum), pericardial sac (pneumopericardium), subcutaneous tissues, or pulmonary veins (Di Maio \& Di Maio, 2001).

Air that enters the pulmonary veins can embolize to the coronary or cerebral arteries (CAGE or cerebral artery gas embolism).

Radiography or computed axial tomography can assist in diagnosing extra-alveolar air in the pleural or pericardial cavities or intravascular locations more easily than the standard postmortem examination.

\section{Conclusion}

Accidents certainly can happen when someone makes a catastrophic mistake, but more often, they begin with a small problem that leads to other problems. The problems then compound until a diver becomes caught up in a cascade of stress and panic, and gets into real trouble.

This may cause the diver to abruptly abort the dive and escape to the surface, letting fear drive him to a rapid ascent that could in turn result in an air embolism, decompression sickness (DCS), or drowning.

The available data on diving accidents leads to the same conclusion: It is generally diver error rather than any design flaw that causes a diving accident. 


\section{References}

Brubakk, A. O., \& Neuman, T. (2002). Physiology and Medicine of Diving (5th ed). WB Saunders.

Froede, R. C. (2003). Handbook of Forensic Pathology (2nd ed.). CAP Press.

Di Maio, V. J. M., \& Di Maio, D. J. (2001). Forensic Pathology (2nd ed.). CRC Press.

Wetli, C. V., Mittleman, R. E., \& Rao, V. J. (1999). An Atlas of Forensic Pathology. ASCP Press. 